\title{
Effects of Zearalenone on IL-2, IL-6, and IFN- $\gamma$ mRNA Levels in the Splenic Lymphocytes of Chickens
}

\author{
Y. C. Wang, ${ }^{1}$ J. L. Deng, ${ }^{1}$ S. W. Xu, ${ }^{2}$ X. Peng, ${ }^{3}$ Z. C. Zuo, ${ }^{4}$ \\ H. M. Cui, ${ }^{3}$ Y. Wang, ${ }^{4}$ and Z. H. Ren $^{4}$ \\ ${ }^{1}$ College of Veterinary Medicine, Sichuan Agricultural University, Yaan, Sichuan 625014, China \\ ${ }^{2}$ Department of Veterinary Medicine, Northeast Agricultural University, Harbin 150030, China \\ ${ }^{3}$ Sichuan Key Laboratory of Animal Disease and Human Health, Yaan, Sichuan 625014, China \\ ${ }^{4}$ Sichuan Key Laboratory of Environmental Hazards Disease, Yaan, Sichuan 625014, China
}

Correspondence should be addressed to J. L. Deng, dengj1213@126.com

Received 17 September 2011; Accepted 22 December 2011

Academic Editors: R. Pohjanvirta and A. Tsatsakis

Copyright ( $) 2012$ Y. C. Wang et al. This is an open access article distributed under the Creative Commons Attribution License, which permits unrestricted use, distribution, and reproduction in any medium, provided the original work is properly cited.

Zearalenone (ZEN) is an estrogenic mycotoxin produced by several Fusarium species, which can contaminate food and feed. These compounds elicit a wide spectrum of toxic effects, including the capacity to alter normal immune function. In this study, the in vitro effects of the treatment of ConA-stimulated splenic lymphocytes with ZEN $(0-25 \mu \mathrm{g} / \mathrm{mL})$ were examined. ZEN modulates the expression of IL-2, IL-6, and IFN- $\gamma$. The IL-2 levels were up to fourfold higher $(P<0.05)$ compared with the levels in the control at toxin concentrations of $25 \mu \mathrm{g} / \mathrm{mL}$ after $48 \mathrm{~h}$ of treatment. The IL- 6 levels were critically suppressed at this concentration; these changes were very statistically significant $(P<0.05)$. At lower ZEN concentrations $(0.1,0.4$ and $1.6 \mu \mathrm{g} / \mathrm{mL})$, the IFN- $\gamma$ levels changed slightly; however at 6.25 and $25 \mu \mathrm{g} / \mathrm{mL}$, the IFN $-\gamma$ results reached statistical significance compared with the control levels $(P<0.05)$. These data suggest that ZEN has potent effects on the expression of chicken splenic lymphocytes cytokines at the mRNA level.

\section{Introduction}

Zearalenone (ZEN) is a mycotoxin produced by several field fungi, including Fusarium graminearum (Gibberella zeae), F. culmorum, F. cerealis, F. equiseti, and F. semitectum $[1,2]$. It exists widely in many cereal crops such as corn, barley, wheat, oats, sorghum, and sesame seeds, as well as in hay and corn silage. These are all ingredients in many food products for human or animal nutrition [3-5].

ZEN is a macrocyclic lactone with a high binding affinity for estrogen receptors. It is biologically potent, but it is hardly toxic. Rather, it has an estrogenic effect that causes alterations in the reproductive tract of laboratory animals (mice, rats, and guinea pigs) and farm animals $[6,7]$. The mechanism of the estrogenic effects of ZEN appears to be mediated via binding of this mycotoxin or its metabolites to the cytoplasmic estrogen receptor [8-10]. This increases cell proliferation [11], resulting in uterine hyperplasia as well as cervical and vaginal metaplasia $[12,13]$.
The immune system is a potential target for estrogenic endocrine disruptors because various cells of the immune system have estrogen receptors [14]. However, only few studies have been carried out regarding the effects of ZEN on spleen immunity in chickens, specifically on lymphocytes. In the present study, we investigated the in vitro effects of ZEN at different concentrations on IL-2, IL-6, and IFN- $\gamma$ mRNA expression levels in poultry spleen lymphocytes.

\section{Materials and Methods}

2.1. Reagents. All chemicals were of the highest grade of purity available. Fetal bovine serum (FBS) was purchased from Sijiqing Biological Engineering Material (Hangzhou, China). Zearalenone, RPMI 1640 medium, and Histopaque 1077 were purchased from Sigma-Aldrich, USA. Trizol reagent was purchased from Invitrogen Biotechnology Co. Ltd. (Shanghai, China). SYBR PremixScript RT-PCR Kit II was purchased from Takara, Shiga, Japan. 
TABLE 1: Real-time PCR primer sequences and products.

\begin{tabular}{lccc}
\hline Gene & Primer & Sequences $\left(5^{\prime} \rightarrow 3^{\prime}\right)$ & Product size $(\mathrm{bp})$ \\
\hline \multirow{2}{*}{-actin } & $\beta$-Actin Forward & CACCACAGCCGAGAGAGAAAT & 135 \\
& $\beta$-Actin Reverse & TGACCATCAGGGAGTTCATAGC & 138 \\
IL-2 & IL-2 Forward & GCTAATGACTACAGCTTATGGAGCA & 106 \\
& IL-2 Reverse & TGGGTCTCAGTTGGTGTGTAGAG & 106 \\
IL-6 & IL-6 Forward & AAATCCCTCCTCGCCAATCT & 132 \\
& IL-6 Reverse & CCCTCACGGTCTTCTCCATAAA & \\
IFN- $\gamma$ & IFN- $\gamma$ Forward & AAGTCATAGCGGCACATCAAAC & \\
& IFN- $\gamma$ Reverse & CTGGAATCTCATGTCGTTCATCG & \\
\hline
\end{tabular}

2.2. Cell Culture. All chickens used in this experiment were approved by the Institutional Animal Care and Use Committee of Northeast Agricultural University. The spleens of twomonth-old Isa Brown chicken were teased through a 200mesh cell strainer into a Petri dish containing phosphatebuffered saline (PBS). The cell suspension was overlaid onto Histopaque 1077 and was centrifuged at $400 \times \mathrm{g}$ for $15 \mathrm{~min}$ at room temperature. The lymphocytes at the interface were collected, washed twice with PBS at $250 \mathrm{~g}$ for $5 \mathrm{~min}$ at room temperature, and suspended in RPMI-1640 medium (without phenol red, a weak estrogen mimic) supplemented with $10 \%$ fetal calf serum, $100 \mathrm{U} / \mathrm{mL}$ penicillin, $100 \mathrm{U} / \mathrm{mL}$ streptomycin. More than $95 \%$ of cells were viable based on the trypan blue dye exclusion. The spleen cells were cultured in 6 -well tissue culture plates $\left(6 \times 10^{6} \mathrm{cell} / \mathrm{mL}\right)$ in triplicate and stimulated with concanavalin A (ConA, $12.5 \mu \mathrm{g} / \mathrm{mL}$, to induce the proliferation of $\mathrm{T}$ cells) at $0,0.1,0.4,1.6$, 6.25 , and $25 \mu \mathrm{g} / \mathrm{mL} \mathrm{ZEN} \mathrm{at} 41.5^{\circ} \mathrm{C}$ in a humidified $5 \% \mathrm{CO}_{2}$

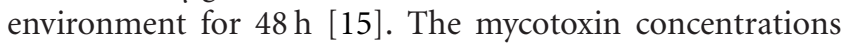
were selected based on preliminary dose-response experiments (data not shown). After $48 \mathrm{~h}$ of incubation, cells were collected for RNA isolation, then frozen at $-80^{\circ} \mathrm{C}$.

2.3. Quantification of $I L-2, I L-6$, and IFN- $\gamma$ mRNA. Total RNA was isolated from cells using Trizol reagent according to the instructions of the manufacturer. The RNA concentrations were determined using the GeneQuant 1300.

The $40 \mu \mathrm{L}$ reverse transcription reaction mixture consisted of the following components: $10 \mu \mathrm{g}$ of total RNA, $1 \mu \mathrm{L}$ of Moloney murine leukemia virus reverse transcriptase, $1 \mu \mathrm{L}$ of RNase inhibitor, $4 \mu \mathrm{L}$ of deoxynucleoside triphosphate, $2 \mu \mathrm{L}$ of Oligo dT, $4 \mu \mathrm{L}$ of dithiothreitol, and $8 \mathrm{~mL}$ of $5 \mathrm{x}$ reverse transcriptase buffer. The reverse transcription was performed according to the instructions of the manufacturer (Invitrogen). The reverse transcription products (cDNA) were stored at $-20^{\circ} \mathrm{C}$ for PCR.

To design primers, we used the chicken IL-2, IL-6, and IFN- $\gamma$ mRNA GenBank sequence with accession numbers of NM204153.1, NM204628.1, and DQ470471.1, respectively. Chicken $\beta$-actin (GenBank accession number L08165.1), a housekeeping gene, was used as the internal reference. The primers (Table 1) were designed using the Prime 5 Software (Molecular Biology Insights, Cascade, CO) and were synthesized by Invitrogen Biotechnology Co. Ltd., Shanghai, China.
Real-time PCR was performed to detect the expression of IL-2, IL-6, and IFN- $\gamma$ genes in different cDNA sample using SYBR Premix Ex Taq (Takara, Shiga, Japan). Each sample was assayed in three replicates. The reaction mixtures were incubated in an ABI PRISM 7500 real-time PCR system (Applied Biosystems, Foster City, CA). The program included 1 cycle at $95^{\circ} \mathrm{C}$ for $30 \mathrm{~s}, 40$ cycles at $95^{\circ} \mathrm{C}$ for $5 \mathrm{~s}$, and $60^{\circ} \mathrm{C}$ for $34 \mathrm{~s}$. The dissociation curves were analyzed using Dissociation curve 1.0 Software (Applied Biosystems) for each PCR reaction to detect and eliminate the possible primer dimer and nonspecific amplification. Results (fold changes) are expressed using the Pfaffl method [16, 17] with the following formula:

$$
\text { Ratio }=\frac{\left(E_{\text {target }}\right)^{\Delta \mathrm{CT}, \text { target (calibrator-test) }}}{\left(\mathrm{E}_{\text {ref }}\right)^{\Delta \mathrm{CT}, \text { ref (calibrator-test) }}}
$$

where $\Delta \mathrm{CT}$, target (calibrator-test $)=\left(\mathrm{CT}_{\text {target }}\right)_{\text {control group }}-$ $\left(\mathrm{CT}_{\text {target }}\right)_{\text {treatment group, }} \Delta \mathrm{CT}$, ref (calibrator-test) $=$ $\left(\mathrm{CT}_{\text {ref }}\right)_{\text {control group }}-\left(\mathrm{CT}_{\text {ref }}\right)_{\text {treatment group }}, \mathrm{E}_{\text {target }}$ is the real-time PCR efficiency of target gene transcript, and $\mathrm{E}_{\mathrm{ref}}$ is the real-time PCR efficiency of a reference gene transcript.

2.4. Statistical Analysis. Statistical analysis of all data was performed using SAS procedures (SAS Institute Inc, NC); differences in mean RT-PCR results were compared by oneway ANOVA. All values are expressed as mean $\pm \mathrm{SD}$, and $P<0.05$ were considered as significant difference.

\section{Results}

To compare the effects of ZEN on cytokine expression in residual living cells among individuals, the results were calculated as mean fold changes in cytokine levels above the control (treated with only ConA) cultures at the same time points. Treatment of the ConA-stimulated cells with ZEN at concentrations ranging from 0 to $25 \mu \mathrm{g} / \mathrm{mL}$ consistently increased the IL-2 levels above those in the ConA-only stimulated cells (Figure 1). These results were statistically significant $(P<0.05)$ with toxin concentrations of $0.1,0.4$, $1.6,6.25$, and $25 \mu \mathrm{g} / \mathrm{mL}$ at $48 \mathrm{~h}$ (Figure 1). In contrast, the ZEN treatment moderately inhibited IL- 6 levels in these cells; these changes were very statistically significant with toxin 


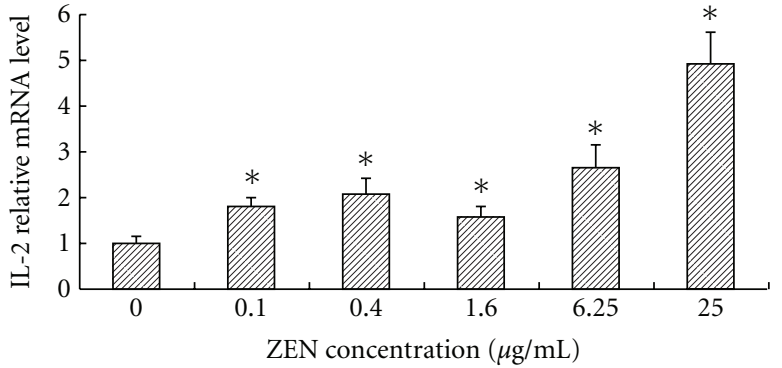

FIgure 1: The effect of ZEN on the IL-2 relative mRNA level in ConA-stimulated lymphocytes at toxin concentration of $0,0.1,0.4$, $1.6,6.25$, and $25 \mu \mathrm{g} / \mathrm{mL}$ at $48 \mathrm{~h}$. The reporter activity in response to ConA alone is expressed as $100 \%$. Values are the means \pm SD from three independent experiments. Statistical analysis was performed using one-way ANOVA followed by Dunnett's post hoc test $\left({ }^{*} P<\right.$ 0.05 versus ConA treated control).

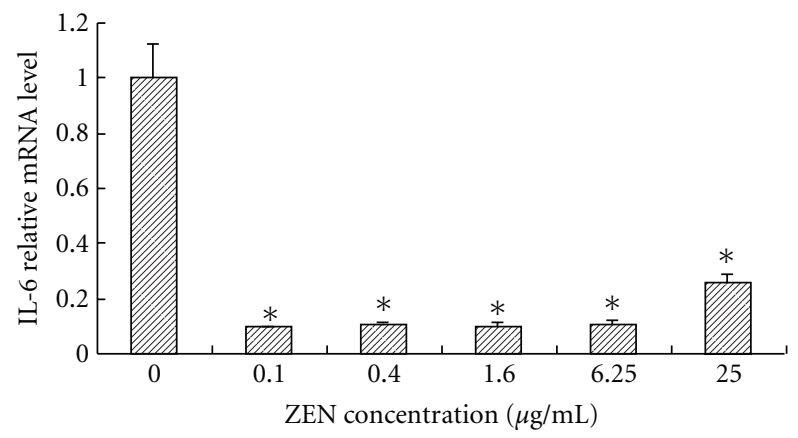

FIgure 2: The effect of ZEN on the IL-6 relative mRNA level in ConA-stimulated lymphocytes at toxin concentrations of $0,0.1,0.4$, $1.6,6.25$, and $25 \mu \mathrm{g} / \mathrm{mL}$ at $48 \mathrm{~h}$. The reporter activity in response to ConA alone is expressed as $100 \%$. Values are the means \pm SD from three independent experiments. Statistical analysis was performed using one-way ANOVA followed by Dunnett's post hoc test $\left({ }^{*} \mathrm{P}<\right.$ 0.05 versus ConA treated control).

concentration in all treated groups $(P<0.05)$. The IL-6 levels were critically suppressed (Figure 2 ).

To understand further the specific effects of ZEN on cytokine profiles, a characteristic TH 1 cytokine, IFN- $\gamma$, was measured in addition to IL-2 and TH 2, IL-6. A lower dose of ZEN $(0.1,0.4$, and $1.6 \mu \mathrm{g} / \mathrm{mL})$ was selected to eliminate the possibility of cytotoxic effects, which contributes to modulation; however, the two highest doses (6.25 and $25 \mu \mathrm{g} / \mathrm{mL}$ ) reached statistical significance compared with the control $(P<0.05)$. The IFN- $\gamma$ levels were slightly suppressed by the ZEN treatment (Figure 3 ).

\section{Discussion}

There is major concern over the potential for mycotoxins to influence poultry negatively. In the present study, the use of cell cultures offers several advantages over other methods, particularly in terms of the quantification of toxic effects and for defining the immune organ specificity related to a preferential action of a particular cell type. We addressed

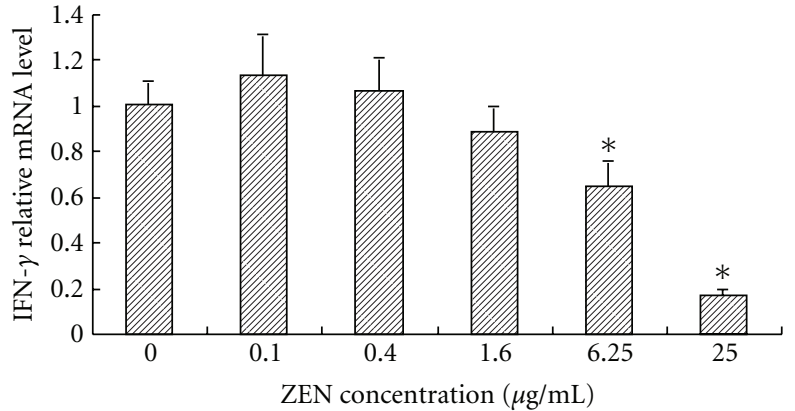

Figure 3: The effect of ZEN on the IFN- $\gamma$ relative mRNA level in ConA-stimulated lymphocytes at toxin concentrations of $0,0.1,0.4$, $1.6,6.25$, and $25 \mu \mathrm{g} / \mathrm{mL}$ at $48 \mathrm{~h}$. The reporter activity in response to ConA alone is expressed as $100 \%$. Values are the means \pm SD from three independent experiments. Statistical analysis was performed using one-way ANOVA followed by Dunnett's post hoc test ( ${ }^{*} P<$ 0.05 versus ConA treated control).

the issue by evaluating the effects of ZEN on the immune function through in vitro assessment of its activity on the splenic lymphocytes of chickens. The splenic lymphocytes of chickens have been a very useful model for different immunologic studies. ConA is a polyclonal T-cell mitogen, and we determined the effects of ZEN on ConA-stimulated lymphocytes on certain T-helper cell (TH), cytokine profiles (IL-2, IL-6, and IFN- $\gamma$ ) were assessed.

To date, there have been no studies regarding the effects of ZEN on the cytokine profiles of chicken splenic lymphocyte. The addition of ZEN in vitro to ConA-stimulated lymphocytes caused a fivefold increase in the expression of IL-2 cytokines at the mRNA level. As the chemical structure of ZEN enables its binding to the estrogenic receptors, our data are not in line with previous results, which indicate that 17-beta-estradiol reduced IL-2 gene transcription in the Jurkat T-cell line [18]. Considering that T-lymphocyte proliferation is essentially mediated by IL-2, the observed inhibition could be considered a primary mechanism of ZEN-induced immunosuppression also acting in vivo. Accordingly, inhibition of the mRNA expression of IL-2 cytokines by $\alpha$-ZEN remain unclear assuming an estrogenlike activity [18]. Our results on IL-2 are not broadly in agreement with studies on cytokine protein expression in humans [19]. However, several alterations in immunologic parameters have been associated with ZEN concentrations in humans [20] and mice [21] including in vitro inhibition of mitogen-stimulated lymphocyte proliferation, increase of IL-2 and IL-5, and induction of immunosuppressive effects $[22,23]$. Alterations in immunologic parameters such as the inhibition of mitogenstimulated lymphocyte proliferation and the increase in IL-2 production were found at high ZEA concentrations in vitro [22]. In addition, populations that are continuously exposed to ZEN may chronically produce IL-2; therefore, IL-6 is decreased. There are only few reports regarding the effects of ZEN on IL-6. Aside from ZEN, Fusarium can also produce other mycotoxins 
such as deoxynivalenol (DON), fumonisin B1 (FB1), and T-2 toxin. The effect of these mycotoxins on IL- 6 has been studied. A study [24] quantified IL-6 in the spleen, ileum, and mesenteric lymph nodes of 24 pigs which received either control feeds or feeds naturally contaminated with $2.2-2.5 \mathrm{mg} / \mathrm{kg}$ of DON feed for 9 weeks using RT-PCR. $\mathrm{FB}_{1}$ inhibited the LPS-induced expression of IL- 6 in human dendritic cells (DCs) [25], whereas the modulation of $\mathrm{FB}_{1}$ toxicity in the brain of female $\mathrm{BALB} / \mathrm{c}$ mice; $\mathrm{FB}_{1}$ augments the LPS-induced IL-6 expression in the brain [26]. The effects of in vivo exposure to T-2 toxin on the alteration of IL6 in lipopolysaccharide-stimulated peritoneal macrophages [27]; IL-6 mRNA from activated peritoneal macrophages showed no significant differences between the control and the treatment groups. The effects of different Fusarium toxins on IL- 6 varied because of differences in toxicities and animal models.

IFN- $\gamma$ is a master cytokine that affects the functioning of all cells of the immune system and plays a major role in host defense against intracellular infections [28]. This cytokine has also been implicated in autoimmune and inflammatory diseases [29]. Importantly, the IFN- $\gamma$ levels in ConA-activated splenic lymphocytes that were exposed to zearalenone decreased after $48 \mathrm{~h}$ of culture, consistent with previous findings. Studies revealed that zearalenone causes a decrease in IFN- $\gamma$ in geriatric mice [30], and a slight reduction in both the mitotic index and the cell survival of bovine lymphocytes [31].

To our knowledge, this is the first study that investigates the effects of ZEN on the cellular immune response of chickens. Although the exact mechanism of action of these toxins is still unknown, the results of the current study suggest that ZEN may have divergent effects on chicken lymphocyte cell viability, and production of IL-2, IL-6 and IFN- $\gamma$. Further studies are needed to elucidate the specific mechanisms by which ZEN affects immune functions.

\section{Disclosure}

All other authors have read the paper and have agreed to submit it in its current form for consideration for publication in The Scientific World Journal.

\section{Acknowledgments}

The present work was supported by the National Natural Science Foundation of China Funds (grant no. 31072182) and the Changjing Scholars \& Innovative Reasearch Team of Ministry of Education of China Funds (Grant no. IRTO848). The authors gratefully acknowledge the members of the Veterinary Internal Medicine Laboratory in the College of Veterinary Medicine, Sichuan Agricultural University, and in College of Veterinary Medicine, Northeast Agricultural University for their help in feeding the laboratory animals and analyzing the data.

\section{References}

[1] J. L. Richard, "Some major mycotoxins and their mycotoxicoses-An overview," International Journal of Food Microbiology, vol. 119, no. 1-2, pp. 3-10, 2007.

[2] J. W. Bennett and M. Klich, "Mycotoxins," Clinical Microbiology Reviews, vol. 16, no. 3, pp. 497-516, 2003.

[3] S. J. Macdonald, S. Anderson, P. Brereton et al., "Determination of zearalenone in barley, maize and wheat flour, polenta, and maize-based baby food by immunoaffinity column cleanup with liquid chromatography: interlaboratory study," Journal of AOAC International, vol. 88, no. 6, pp. 17331740, 2005.

[4] G. Engelhardt, J. Barthel, and D. Sparrer, "Fusarium mycotoxins and ochratoxin A in cereals and cereal products: results from the Bavarian Health and Food Safety Authority in 2004," Molecular Nutrition and Food Research, vol. 50, no. 4-5, pp. 401-405, 2006.

[5] C. Tabuc, D. Marin, P. Guerre, T. Sesan, and J. D. Bailly, "Molds and mycotoxin content of cereals in southeastern romania," Journal of Food Protection, vol. 72, no. 3, pp. 662-665, 2009.

[6] U. Tiemann and S. Dänicke, "In vivo and in vitro effects of the mycotoxins zearalenone and deoxynivalenol on different nonreproductive and reproductive organs in female pigs: a review," Food Additives and Contaminants, vol. 24, no. 3, pp. 306-314, 2007.

[7] F. Minervini and M. E. D. Aquila, "Zearalenone and reproductive function in farm animals," International Journal of Molecular Sciences, vol. 9, no. 12, pp. 2570-2584, 2008.

[8] B. S. Katzenellenbogen, J. A. Katzenellenbogen, and D. Mordecai, "Zearalenones: characterization of the estrogenic potencies and receptor interactions of a series of fungal $\beta$-resorcylic acid lactones," Endocrinology, vol. 105, no. 1, pp. 33-40, 1979.

[9] S. O. Mueller, "Overview of in vitro tools to assess the oestrogenic and antioestrogenic activity of phytooestrogens," Journal of Chromatography B, vol. 777, no. 1-2, pp. 155-156, 2002.

[10] U. Tiemann, T. Viergutz, L. Jonas, and F. Schneider, "Influence of the mycotoxins $\alpha$ - and $\beta$-zearalenol and deoxynivalenol on the cell cycle of cultured porcine endometrial cells," Reproductive Toxicology, vol. 17, no. 2, pp. 209-218, 2003.

[11] D. S. Coffey, "Similarities of prostate and breast cancer: evolution, diet, and estrogens," Urology, vol. 57, no. 4, supplement 1, pp. 31-38, 2001.

[12] M. Gajecki, "Zearalenone-undesirable substances in feed," Polish Journal of Veterinary Sciences, vol. 5, no. 2, pp. 117-122, 2002.

[13] W. Zwierzchowski, M. Przybyłowicz, K. Obremski et al., "Level of zearalenone in blood serum and lesions in ovarian follicles of sexually immature gilts in the course of zearalenone micotoxicosis," Polish Journal of Veterinary Sciences, vol. 8, no. 3, pp. 209-218, 2005.

[14] H. Igarashi, T. Kouro, T. Yokota, P. C. Comp, and P. W. Kincade, "Age and stage dependency of estrogen receptor expression by lymphocyte precursors," Proceedings of the National Academy of Sciences of the United States of America, vol. 98, no. 26, pp. 15131-15136, 2001.

[15] M. Okamura, H. S. Lillehoj, R. B. Raybourne, U. S. Babu, and R. A. Heckert, "Cell-mediated immune responses to a killed Salmonella enteritidis vaccine: lymphocyte proliferation, Tcell changes and interleukin-6 (IL-6), IL-1, IL-2, and IFN$\gamma$ production," Comparative Immunology, Microbiology and Infectious Diseases, vol. 27, no. 4, pp. 255-272, 2004. 
[16] W. P. Michael, "A new mathematical model for relative quantification in real-time RT-PCR," Nucleic Acids Research, vol. 29, no. 900, pp. 2004-2007, 2001.

[17] S. Čikoš, A. Bukovská, and J. Koppel, "Relative quantification of mRNA: comparison of methods currently used for realtime PCR data analysis," BMC Molecular Biology, vol. 8, article 113, 2007.

[18] R. W. McMurray, K. Ndebele, K. J. Hardy, and J. K. Jenkins, "17- $\beta$-estradiol suppresses IL-2 and IL-2 receptor," Cytokine, vol. 14, no. 6, pp. 324-333, 2001.

[19] D. Luongo, L. Severino, P. Bergamo, R. De Luna, A. Lucisano, and M. Rossi, "Interactive effects of fumonisin B1 and $\alpha$ zearalenol on proliferation and cytokine expression in Jurkat T cells," Toxicology in Vitro, vol. 20, no. 8, pp. 1403-1410, 2006.

[20] L. Berek, I. B. Petri, Á. Mesterházy, J. Téren, and J. Molnár, "Effects of mycotoxins on human immune functions in vitro," Toxicology in Vitro, vol. 15, no. 1, pp. 25-30, 2001.

[21] M. L. Marin, J. Murtha, W. Dong, and J. J. Pestka, "Effects of mycotoxins on cytokine production and proliferation in EL-4 thymoma cells," Journal of Toxicology and Environmental Health, vol. 48, no. 4, pp. 379-396, 1996.

[22] G. S. Eriksen and J. Alexander, Eds., Fusarium Toxins in Cereals_-A Risk Assessment, vol. 502, Nordic Council of Ministers, Copenhagen, Denmark, 1998.

[23] H. Murata, P. Sultana, N. Shimada, and M. Yoshioka, "Structure-activity relationships among zearalenone and its derivatives based on bovine neutrophil chemiluminescence," Veterinary and Human Toxicology, vol. 45, no. 1, pp. 18-20, 2003.

[24] P. Pinton, F. Accensi, E. Beauchamp et al., "Ingestion of deoxynivalenol (DON) contaminated feed alters the pig vaccinal immune responses," Toxicology Letters, vol. 177, no. 3, pp. 215-222, 2008.

[25] H. Stockmann-Juvala, H. Alenius, and K. Savolainen, "Effects of fumonisin $\mathrm{B} 1$ on the expression of cytokines and chemokines in human dendritic cells," Food and Chemical Toxicology, vol. 46, no. 5, pp. 1444-1451, 2008.

[26] M. F. Osuchowski, Q. He, and R. P. Sharma, "Endotoxin exposure alters brain and liver effects of fumonisin B 1 in BALB/c mice: implication of blood brain barrier," Food and Chemical Toxicology, vol. 43, no. 9, pp. 1389-1397, 2005.

[27] R. R. Dugyala and R. P. Sharma, "Alteration of major cytokines produced by mitogen-activated peritoneal macrophages and splenocytes in T-2 toxin-treated male CD-1 mice," Environmental Toxicology and Pharmacology, vol. 3, no. 1, pp. 73-81, 1997.

[28] J. E. Durbin, T. R. Johnson, R. K. Durbin et al., "The role of IFN in respiratory syncytial virus pathogenesis," The Journal of Immunology, vol. 168, no. 6, pp. 2944-2951, 2002.

[29] N. H. R. Hamilton, J. L. Banyer, A. J. Hapel et al., "IFN- $\gamma$ regulates murine interferon-inducible $\mathrm{T}$ cell alpha chemokine (I-TAC) expression in dendritic cell lines and during experimental autoimmune encephalomyelitis (EAE)," Scandinavian Journal of Immunology, vol. 55, no. 2, pp. 171-177, 2002.

[30] J. Calemine, J. Zalenka, E. Karpuzoglu-Sahin, D. L. Ward, A. Lengi, and S. A. Ahmed, "The immune system of geriatric mice is modulated by estrogenic endocrine disruptors (diethylstilbestrol, $\alpha$-zearalanol, and genistein): effects on interferon- $\gamma$," Toxicology, vol. 194, no. 1-2, pp. 115-128, 2003.

[31] M. B. Lioi, A. Santoro, R. Barbieri, S. Salzano, and M. V. Ursini, "Ochratoxin A and zearalenone: a comparative study on genotoxic effects and cell death induced in bovine lymphocytes," Mutation Research, vol. 557, no. 1, pp. 19-27, 2004. 

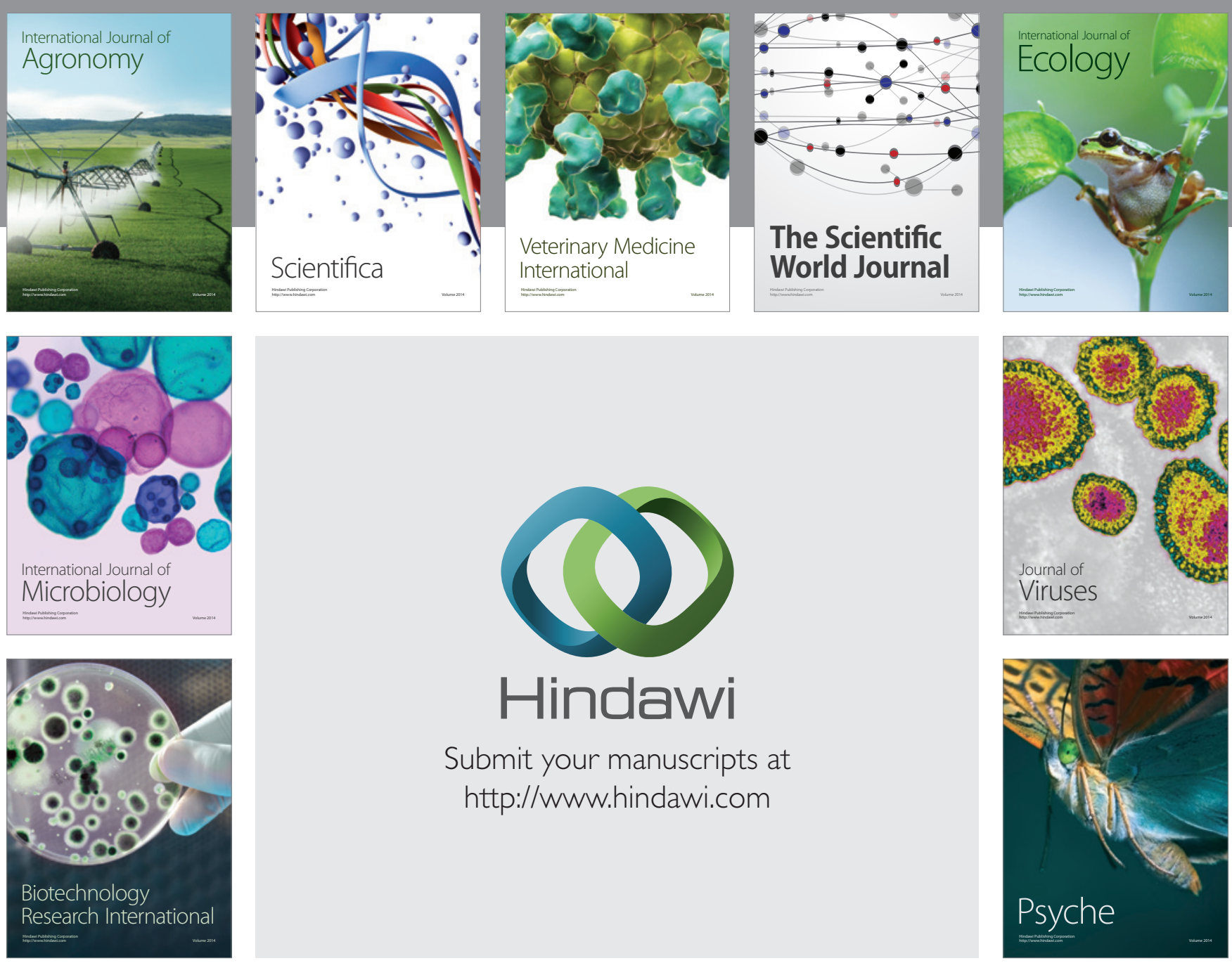

Submit your manuscripts at

http://www.hindawi.com
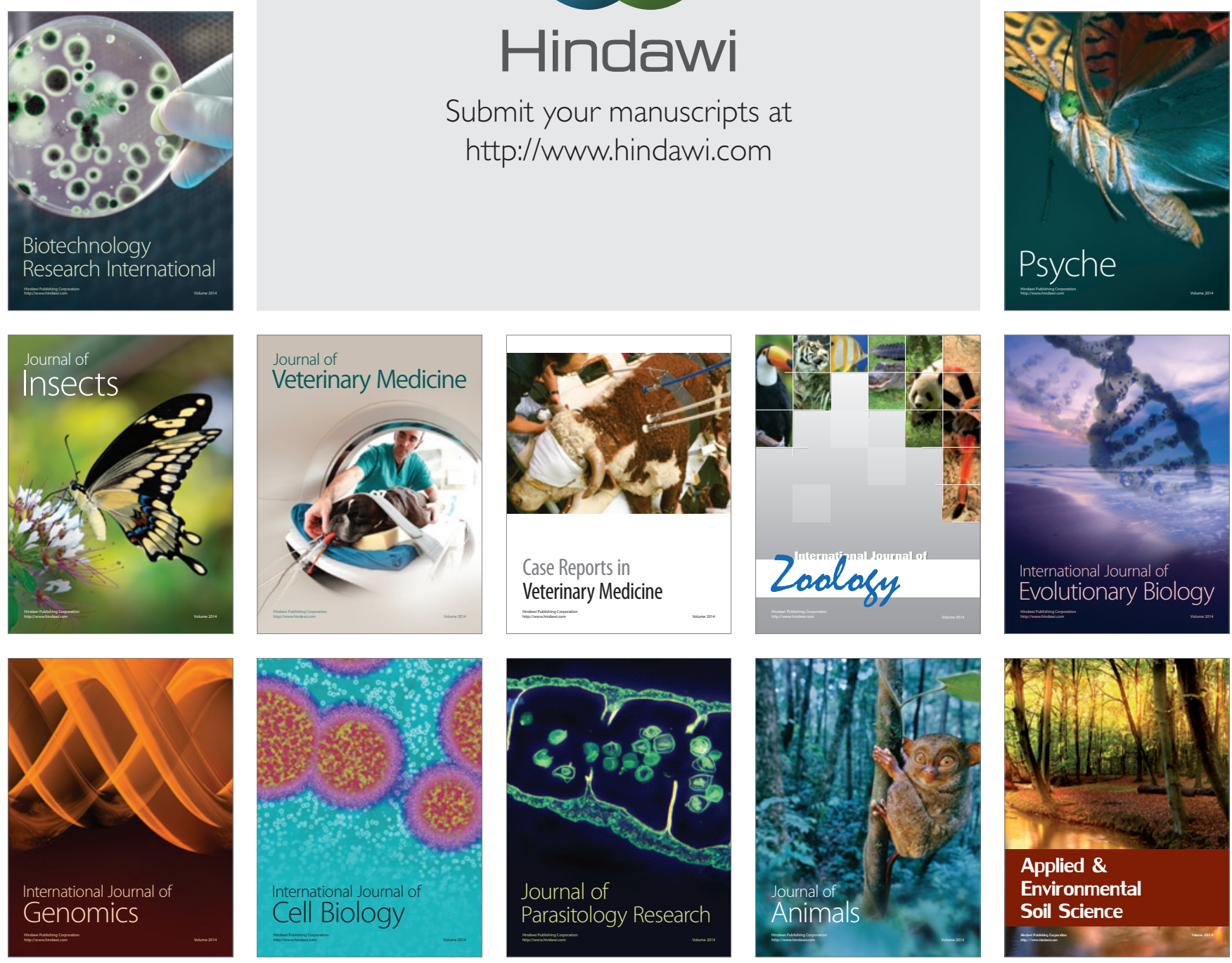